\title{
Tetracycline treatment for non-specific urethritis
}

\author{
J. CH. SIMOPOULOS \\ From St Catherine's College, Oxford
}

SUMmARY The conclusions, where pertinent, of the 10 papers on the treatment of non-specific urethritis which have appeared in the British Journal of Venereal Diseases between 1971 and now are reviewed. Recent studies purport to argue, but in fact assume, that tetracycline treatment for non-specific urethritis is both effective and desirable; current practice agrees with this assumption. To prove effectiveness, studies over much longer follow-up periods would be necessary. These studies should compare results not only of different methods and doses of tetracycline, of different regimens, and of different types of the drug; they should also compare results over a prolonged period with placebos and with other drugs, for instance those outside the antibiotic range and with no suspected side effects. Only then would it be reasonable to hold a firm view on the desirability or the effectiveness of the treatment. With patience and properly conducted experiments results may emerge to justify some view. At the moment the data are ill-assembled although voluminous and fail to support conclusions that have any clarity or force; moreover they are so haphazard that they cannot be compared with one another. Some venereologists are sceptical about treatment, some advocate the administration of one single dose, others say the four- or five-day regimen is preferable, and so on up to those who maintain that the 21-day regimen is the best. The coexistence of such mutually incompatible, firmly-held views may well suggest that the whole system of investigation put together to validate such views is quite inappropriate. That would be a radical thesis, and perhaps none the worse for that. What is not a radical thesis, however, is that at present the whole system of data and argument is in disarray.

\section{Introduction}

Ten papers on the treatment of non-specific urethritis have been published in the British Journal of Venereal Diseases since 1971. In view of the epidemiological importance of this condition and the present world-wide interest in it, these papers are reviewed; they are dealt with in chronological order.

The first, by Lassus et al. (1971), can be dismissed because no control group was involved, the assessment time was too soon after the initial treatment, and the experiment was not rigorous. There was however one cautionary sentence (p. 129): 'The longer the follow-up period, the more difficult it is to judge correctly the treatment results, since spontaneous remissions and recurrences are more prone to interfere'.

In the paper by John (1971), the alleged effects of treatment with three different regimens of oxytetracycline are discussed. An $87 \%$ cure rate at the end

Address for reprints: J. Ch. Simopoulos, St Catherine's College, Oxford

Received for publication 24 March 1977 of three months is claimed as a result of 21 days' administration of oxytetracycline, as opposed to $55 \%$ and $72 \%$ for five and 10 days' administration respectively. This finding would be impressive if it were not weakened by neglect to give the number of defaulters and by the fact that 'there was no attempt to distinguish treatment failure from reinfection' (p. 267).

Masterton and Schofield (1972) conducted experiments using a single dose of $\mathbf{3 0 0} \mathrm{mg}$ of doxycycline. Unfortunately, here too, the figures, although copious, must incline the reader to caution. For instance, on p. 122, it is stated that "five patients with gonorrhoea and 12 with non-specific urethritis failed to return after treatment. A further 23 $(21.4 \%)$ of those with gonorrhoea (Table II) and $37(27 \cdot 7 \%)$ of those with non-specific urethritis (Table III) completed only one week's surveillance.' In fact it is not 'a further' 23 and 37 , for these figures include 5 and 12 respectively. Furthermore, for 37 read 31. To their credit the authors did refrain from writing until they could complete a long-term assessment at the end of a 12-month period of surveillance (p. 124). This longterm- 
assessment shows a success-rate of $88.8 \%$. When it is remembered that this length of time favours both reinfection and relapse (but also, of course, spontaneous remission) this is an impressive figure and renders highly questionable all the lengthier regimens that have remained popular.

The investigation by Bhattacharyya and Morton (1973) is, it is to be feared, no evidence of anything. The 191 patients in the four-day oxytetracycline group with which 107 patients in the 21-day Deteclo treated group were compared 'were found to match the study group in all respects except past history; their incidence of NSU was only half that of the present study group' (p. 522). This debonair dismissal of a staggering difference renders doubtful the seriousness of that investigation.

The work by Ford and Smith (1974) referred to one single patient, and accordingly is of little concern.

Grimble and Amarasuriya (1975) experimented with a number of treatment regimens. Their two most important findings were that: 'the use of the drug for three weeks by us in a few cases did not result in an increased success (see Table I, footnote)' (p. 200 ), and the placebo cure-rate was easily the lowest. But these findings too are vitiated by the fact that two weeks only was the time allowed for 'cure' (except in the case of the 21-day oxytetracycline treatment).

The purpose of the trial done by Perera (1975) was to compare sustained-release oral tetracycline with encapsulated non-sustained-release oxytetracycline, the treatment in each case lasting for five days. The results are hardly startling, and are not germane to the subject.

In the study by Helmy and Fowler (1975) four treatments were described: (1) tetracycline $(500 \mathrm{mg})$ four times a day for seven days, (2) tetracycline $(250 \mathrm{mg}$ ) four times a day for 14 days, (3) Deteclo $(300 \mathrm{mg})$ three times a day for 21 days, and (4) oxytetracycline $(250 \mathrm{mg})$ four times a day for four days.

The failure rate (at 21 days except in the case of Deteclo, for which it was at 28 days) ranged only from $19.1 \%$ to $24.0 \%$ (population ranges: $131-274)$. The recurrence rate ranged from $2 \cdot 2 \%$ in (3) treatment to $8.4 \%$ in (2) treatment. Since, however, the method of counting cases of recurrence was not specified, we can draw no firm conclusion from these results. That drawn by the authors was that 'traditional' low-quantity short treatment was not inferior to other forms of treatment.

The article by Prentice et al. (1976) was partly concerned with the aetiology of non-specific urethritis. As regards treatment, it compared mino- cycline with a placebo, the treatment lasting six days. 'The interval beiween taking specimens was on average 8.5 days (range 7-21)' (p. 270).

Finally, in the study by Evans (1977) the results were compared of seven-day treatments with (1) oxytetracycline $(250 \mathrm{mg})$ twice daily, (2) Deteclo (one tablet) twice daily, and (3) Sustamycin (one tablet) twice daily. The noteworthy features of the study were that: the doses were smaller than in other studies-although the results were similar to those associated with larger doses and prolonged treatments, and (p. 42) the author stated that the follow-up period should be greater than three months.

\section{Conclusions}

There are five points which emerge from examination of these papers.

1. There is in some of these studies a semblance of experimental rigour, but it is only a semblance. In others there is not even that.

2. The fact that the results of similar experiments vary enormously suggests that the treatment itself is only one of several factors affecting the course of the disease. The effectiveness of each treatment is not, therefore, demonstrated and should not be assumed. This makes any comparative study meaningless.

3. Lip-service is paid (passim) to the observation that patterns of recurrence are such as to make any tetracycline treatment of doubtful superiority over others. With one exception, no long-term study was considered relevant to the evaluation of results.

4. The work of Masterton and Schofield (1972) was not once referred to in the subsequent literature, although it had two outstanding features not to be found elsewhere: it investigated a single-dose oral treatment which looks as though it may be the most effective of all the tetracycline treatments (the high cost per gram of the product can hardly be a serious argument in favour of the universal silence with which this study has been received), and it alone, apart from the recent article by Evans (1977), talked seriously of a 12-month follow-up.

5. The one long-term study (Masterton and Schofield, 1972) did not use as an element in its comparison a placebo-regimen. That may be the most interesting comparison of them all.

\section{References}

Bhattacharyya, M. N., and Morton, R. S. (1973). Long-term triple tetracycline (Deteclo) treatment of non-specific urethritis. British Journal of Veneral Diseases, 49, 521-523. 
Evans, B. A. (1977). The role of tetracyclines in the treatment of non-specific urethritis. British Journal of Venereal Diseases, 53, $40-43$.

Ford, D. K., and Smith, J. R. (1974). Non-specific urethritis associated with a tetracycline-resistant T-mycoplasma. British Journal of Venereal Diseases, 50, 373-374.

Grimble, A. S., and Amarasuriya, K. L. (1975). Non-specific urethritis and the tetracyclines. British Journal of Venereal Diseases, 51, 198-205.

Helmy, N., and Fowler, W. (1975). Intensive and prolonged tetracycline therapy in non-specific urethritis. British Journal of Venereal Diseases, 51, 336-339.

John, J. (1971). Efficacy of prolonged regimens of oxytetracycline in the treatment of nongonococcal urethritis. British Journal of Venereal Diseases, 47, 266-268.
Lassus, A., Perko, R.-L., Stubb, S., Mattila, R., and Jansson, E. (1971). Doxycycline treatment of nongonococcal urethritis with special reference to $\mathrm{T}$-strain mycoplasmas. British Journal of Venereal Diseases, 47, 126-130.

Masterton, G., and Schofield, C. B. S. (1972). Doxycycline $\mathrm{HCl}$ (Vibramycin) as a single dose oral treatment of gonococcal and nonspecific urethritis in men. British Journal of Venereal Diseases, 48, 121-125.

Perera, P. M. (1975). Evaluation of a sustained-release oral tetracycline in non-specific urethritis. British Journal of Venereal Diseases, 51, 333-335.

Prentice, M. J., Taylor-Robinson, D., and Csonka, G. W. (1976). Non-specific urethritis. A placebo-controlled trial of minocycline in conjunction with laboratory investigations. British Journal of Venereal Diseases, 52, 269-275. 